The observations of many years enable us to confirm the remarks of Dr. Hubbard relative to its virtues in aphthous affections.

In thrush in children, it is itself a remedy not inferior to borax, which has been so long in universal use. In those cases of Fluor Albus which are attended with aphthous eruptions, it has been found as uniformly profitable as any remedy of its kind of power ; and as generally corrective, as abiding and still operating causes of this eruption would allow. In those cases of Fluor Albus which depend on prolapsus, or descent of the womb into the vagina, which constitute no sniall proportion, there is probably not a better astringent lotion in use than its stronger preparations, for permanently correcting that relaxation of the vagina which exists in these cases.

In obstinate diarrhœa, the bark of the root has been long in successful use. In the troublesome discharge and ulcerations of the second stage of salivation, it has been long and successfully administered. The strong decoction of the bark of the root, also the bark of the fresh root itself, have been found by experience amongst the most valuable styptics in dornestic use, for restraining hæmorrhage from wounds. A tea of the leaves and flowers, sweetened with fine sugar, \&c. which is not an unacceptable offering to the palate and stomach, is finely adapted to diarrhoa and relaxation of the bowels generally, particularly in children, and those troublesome habitual cases unattended with febrile action, in which we have reason to apprehend the presence of aphthæ, or ulceration, in the mucous membrane of the intestines.

It has also been found useful in those highly dangerous cases of hypercatharsis induced by the ruinous power of lobelia in the hands of the Thomsonians, and which so often ends in permanent relaxation of bowels and loss of all powers of nutrition, and consequent death.

In such cases, a tea of the leaves and flowers may be very advantageously prescribed, more or less exclusively, as a diet. This tea will generally be found not only admissible, but remedial in those cases of dyspepsia in which the bowels are perpetually relaxed, and the digestive and nutritive functions suspended.

\title{
CASES, WITH OBSERVATIONS.
}

BY F. M. ROBERTSON, M.D. OF A UGUSTA, GEO.

Those who have devoted their attention, in any degree, to the subject of Phrenology, are aware of the function assigned to the cerebellum, in the arrangement of this system. The science not only recognizes separate and distinct elementary faculties, but these faculties are manifested by means of separate and distinct cerebral organs. Appeals are made, by those who advocate the science, not only to the physiological laws which govern the progressive development and decline of the encephalic mass, but also to its anatomical structure, the pathological state of the organs, and the derangement in the manifestations of the functions dependent thereon. From these sources, a mass of evidence may be accumulated, which 
will almost set opposition at defiance ; for one fact is worth a volume of abstract reasoning; and, while the flimsy tissue, of which the latter is composed, is made to vanish before the superior light of truth and observation, the former stands unaltered in its intrinsic nature.

Many cases, having the same bearing upon this,point, as the two we are about to relate, may be found in the surgical observations of Baron Larrey-some of them are so remarkable, and apparently unnatural, that they would at once appear questionable, was it not that the veracity of the author stands "above suspicion."

Case 1st. On the 6th of October, 1834, I was called to a negro man between thirty-five and forty years of age, who had fallen through a dray while his horse was in motion. In descending, the back of his bead and neck struck one of the cross-bars of the vehicle with such force as to produce a severe concussion and fracture of the fourth and fifth vertebræ of the neck. The details of the case, so far as relates to the symptoms consequent upon the fracture of the vertebræ and compression of the spinal marrow, and the appearances on dissection, are recorded in another Medical Journal.* The patient lived thirty-three hours after the accident occurred. On the day after the injury was received, from his having voided no urine, a distension of the bladder was feared, to obviate which the introduction of the catheter was proposed. On examining the parts, previous to the introduction of the iustrument, the penis was found to be in a state of rigid erection. The catheter was introduced, but no urine followetl. The penis continued in a state of priapism until the death of the patient, and though the instrument was introduced repeatedly, not more than an ounce of urine came away. Upon pressure above the pubes, no marks of a distended bladder could be observed. No twitching of the muscles, or the slightest convulsion, occurred during the progress of the case; so that the priapism could not be accounted for upon the grounds of a spasmodic action. Doctors Cunningham, Patterson, and J. E. Bacon, visited the case with me, and the two last-named gentlemen witnessed the introduction of the catheter. Independent of the fracture of the spine, a severe blow was received immediately over the region of the cerebellum. It is to be regretted that the examination, post mortem, could not have been carried beyond the fractured portion of the spine; but as this was performed clandestinely, it was inpossible, under the circumstances, to proceed further.

Case 2d. This case occurred during the late Seninole campaign, and was related to me by Dr. Ogleby, the Surgeon to the Georgia Battalion of Volunteers under Major Cooper. In the engagement with the Indians, in what is termed the cove of the Ouithlacoochee, on the morning of the 31st March, Mr. Robinson, a member of the Louisiana Volunteers, received a rifle ball in the back of the head. It entered behind the ear, immediately over the region of the cerebellum, and penetrated through the skull, and was supposed, by his medical attendants, to have lodged in the substance of this portion of the encephalon. His symptoms were those usually developed by such injuries, and contrary to the

- Nurth American Archives, vol. 18t, page 391. 
expectations of his friends, he lived several days after the wound was received, notwithstanding the unfavorable circumstances under which the army labored relative to hospital comforts and suitable transportation for the sick. As the main body of the army took up the line of march for Tampa Bay, on the Ist of A pril, he was left under the care of Dr. Ogleby, at Fort Cooper. In the progress of the case, the Doctor found it necessary, in consequence of the accumulation of urine in the bladder, to introduce the catheter; and, to his surprise, when the penis was exposed, for the purpose of performing the operation, it was found to be in a state of rigid erection. The instrument was introduced and the urine evacuated, but the penis remained in a state of permantnt erection until the death of the patient. The reaction, of course, was considerable after the reception of the injury, and it is reasonable to suppose that the portion of the encephalon nearest the foreign body must have suffered most, from the consequent inflammation.

In this case one might suppose that the priapism was occasioned, partly, by the stimulus of the excessive quantity of urine accumulated in the bladder; but this supposition is completely set aside by the first case, in which no urine at all was secreted for nearly thirty-three hours, and yet the priapism was as complete as in the second case; and again, in the latter case, the evacuation of the urine produced no change whatever in this singular symptom.

Those who have any curiosity to look further into this singnlar subject, are referred to the work of Gall on the functions of the brain, Spurzheim's systern of phrenology, and Baron Larrey's surgical observations. The object of this article is not to discuss the principles of phrenology, or to enter into an elaborate defence of the science, against the many unfounded and unjust imputations which have been brought against it, but merely to give two cases, which certainly claim some merit as facts in proof of the science. Many of our readers will be inclined, no doubt, to underrate the bearing which these cases have upon the point in question, but we feel assured that strict observation cannot fail to render almost positive, even with the most skeptical, many of the positions maintained by the adrocates of the doctrine; for the truth of the fundamental principles of phrenology may now be considered as established upon too firm a foundation to be overthrown by the ridicule of its opponents. The science has recovered from the momentary shock which was given to it by this once powerful engine. Facts are now looked upon as more important than opinions, though the latter may clain high sources as their origin, and appeal to the consecration of antiquity. These are no longer a barrier to the investigator into the laws of nature, and fashion now possesses no terror to him, who, seeking for truth, resorts to the universal volume, in which the hand of Infinite Wisdom has inscribed His immutable laws. The science of phrenology is based upon observation, and our opponents must resort to the same course before they can hope to arrive at their ultimate end. Ridicule we do not fear, and an appeal to observation is all we ask. If the science be contrary to facts, let it perish ; but, if supported by the truths of nature, its own omnipotence will vanquish every foe.- Southern Med. and. Sur. Jour. 